\title{
Relationship Between Anatomical and Functional Assessments of Coronary Artery Stenosis
}

\author{
Nobuhiro Tanaka, MD, PhD
}

$\mathbf{T}$ he information obtained from a coronary angiogram is essential for determining the treatment strategy of ischemic heart disease. However, the coronary angiogram has some limitations because it is a form of luminology. Therefore, we use a non-invasive stress test in conjunction with angiography before percutaneous coronary intervention (PCI) to determine the significance of the stenosis. To supplement the angiogram, intracoronary imaging techniques, including intravascular ultrasound (IVUS), intracoronary angioscopy, and optical coherence tomography (OCT), have been developed.

\section{Article p2218}

OCT shows great potential in determining the composition of the plaque, because of its high spatial resolution $(10-15 \mu \mathrm{m})$. Since OCT has become commercially available, the number of OCT studies has been increasing as a result of the interest in identifying high-risk plaques and stratifying their progno$\operatorname{sis}^{1,2}$ On the other hand, IVUS has been used clinically since the early $1990 \mathrm{~s}$ in Japan to measure minimum lumen area (MLA), plaque area, and longitudinal extension of the plaque, as well as to observe the geometry of vessel remodeling. Many researchers have reported a relationship between MLA evaluated by IVUS and the physiological significance of the stenosis assessed by fractional flow reserve (FFR). ${ }^{3,4}$ In the reports, these 2 factors correlate well, but the scatter varies widely, emphasizing that the anatomical severity of the stenosis is essentially different from its functional significance. This difference should thus be taken into consideration when such parameters are compared.

The concept of FFR was first introduced by Nico Pijls as an index for the functional significance of coronary artery stenosis. ${ }^{5}$ FFR is defined as the ratio of maximum blood flow in a stenotic artery relative to maximum blood flow in its normal state. In other words, FFR represents the degree by which the maximum blood flow is limited in the presence of a stenosis. For example, if FFR is 0.75 , maximum blood flow reaches only $75 \%$ of its normal value. FFR can be calculated as the ratio of distal pressure over aortic pressure obtained during maximum hyperemia. FFR indicates the significance of the lesion in every vessel, during the entire PCI procedure. ${ }^{6}$ In patients with multivessel disease, FFR allows us to grade the functional severity and to predict the outcome of the patient after PCI. The use of FFR has been reported to aid in decision making for achiev- ing a favorable revascularization outcome. ${ }^{7}$ Thus, FFR-guided PCI has been upgraded to an IA classification for multivessel disease in the Guidelines on Coronary Revascularization of the European Society of Cardiology. ${ }^{8}$

Theoretically, the pressure drop across a stenosis is influenced by many factors: lumen cross-sectional area, lesion length, the shape of the entrance and exit orifices, vessel stiffness and the distensibility of the diseased segment, blood viscosity and blood density. ${ }^{9}$ It is difficult to predict the degree of pressure drop from only one of these anatomical indices. Moreover, a pressure drop depends on the blood flow across the stenosis and varies according to the amount of perfusion territory, even in cases of the same anatomical severity. ${ }^{4}$ Stenosis in a vessel that perfuses a larger territory, such as the left main trunk, causes a larger pressure drop. The cut-off value for the functional significance of anatomical indices should thus differ relative to the lesion's location and the individual patient. When MLA is used to judge the significance of the stenosis, particular attention is needed.

IVUS has been widely applied to determine the mechanism of balloon dilation or restenosis, thereby contributing to dramatic development of PCI. Despite such advances, diagnosis of vulnerable plaque and prognosis of the plaque by IVUS are still difficult. As OCT has a 10-fold higher spatial resolution than IVUS, its progress has made it possible to depict the lipid core and measure the thickness of the fibrous cap. The plaques most prone to rupture are thin-cap fibroatheromas (TCFAs), which are characterized by a thin fibrous cap $(<75 \mu \mathrm{m}$ thickness). ${ }^{1}$ Thus, diagnosis of TCFAs using OCT is expected for risk stratification of plaque rupture. Moreover, OCT may allow exploration of the cause of late failure of a drug-eluting stent (DES), as its high resolution images can delineate the fine details of the surface of stent struts. Recent studies have revealed the possible effect of the healing process and neoatherosclerosis after DES implantation on late stent failure. ${ }^{10,11}$

The application of OCT in identifying the hemodynamic significance of a stenosis is unclear. Its higher spatial resolution may offer much clearer identification of the lumen border, but very little data are available concerning the efficacy of OCT findings in assessing the significance of a stenosis. ${ }^{12}$ In this issue of the Journal, Shiono et $\mathrm{al}^{13}$ attempt to address this issue by comparing OCT findings with FFR. They found that MLA, minimum lumen diameter (MLD) and percent lumen area stenosis measured by OCT correlated well with FFR values; the best cutoff values measured by OCT to identify stenoses with

The opinions expressed in this article are not necessarily those of the editors or of the Japanese Circulation Society.

Received July 10, 2012; accepted July 11, 2012; released online July 24, 2012

Department of Cardiology, Tokyo Medical University, Tokyo, Japan

Mailing address: Nobuhiro Tanaka, MD, PhD, Department of Cardiology, Tokyo Medical University, 6-7-1 Nishi-shinjuku, Shinjuku-ku,

Tokyo 160-0023, Japan. E-mail: n-tanaka@tokyo-med.ac.jp

ISSN-1346-9843 doi:10.1253/circj.CJ-12-0896

All rights are reserved to the Japanese Circulation Society. For permissions, please e-mail: cj@j-circ.or.jp 
FFR $<0.75$ were $1.91 \mathrm{~mm}^{2}, 1.35 \mathrm{~mm}$ and $70.0 \%$, respectively. The cutoff values for MLA and MLD were smaller than those previously reported for IVUS. ${ }^{3,4}$ This variation could be related to the influence of the balloon occlusion proximal to the stenosis, which is needed to perform time-domain OCT. Balloon occlusion could reduce intracoronary pressure and make smaller vessels compared with those under physiological conditions. However, using frequency-domain OCT, the optimal cutoff value of MLA to predict FFR $<0.80$ was determined to be $1.95 \mathrm{~mm}^{2}$, which was also lower than the IVUS-derived cutoff value. ${ }^{12}$ There appear to be fundamental differences between the OCT and IVUS measurements of MLA.

Overall, when comparing anatomical indices with functional indices, we should take into account the lesion's location and vessel territory. Moreover, we should emphasize the influence of variation because of race, sex and the individual on the threshold of anatomical indices. As it is impossible to completely predict the functional severity from one index for anatomical observations, appropriate use of multiple modalities is recommended for each case. Although there are still limitations for clinical use with regard to its functional information, OCT is an established technique that provides a great deal of anatomical information.

\section{References}

1. Uemura S, Ishigami K, Soeda T, Okayama S, Sung JH, Nakagawa H, et al. Thin-cap fibroatheroma and microchannel findings in optical coherence tomography correlate with subsequent progression of coronary atheromatous plaques. Eur Heart $J$ 2012; 33: 78-85.

2. Miyazaki S, Hiasa Y, Takahashi T, Yano Y, Minami T, Murakami N, et al. In vivo optical coherence tomography of very late drug-eluting stent thrombosis compared with late in-stent restenosis. Circ J 2012; 76: $390-398$.

3. Takagi A, Tsurumi Y, Ishii Y, Suzuki K, Kawana M, Kasanuki H. Clinical potential of intravascular ultrasound for physiological assessment of coronary stenosis: Relationship between quantitative ultrasound tomography and pressure-derived fractional flow reserve. Cir- culation 1999; 100: 250-255.

4. Koo BK, Yang HM, Doh JH, Choe H, Lee SY, Yoon CH, et al. Optimal intravascular ultrasound criteria and their accuracy for defining the functional significance of intermediate coronary stenoses of different locations. J Am Coll Cardiol Interv 2011; 4: 803-811.

5. Pijls NHJ, De Bruyne B, Peels K, van der Voort PH, Bonnier HJRM, Bartunek J, et al. Measurement of fractional flow reserve to assess the functional severity of coronary artery stenoses. N Engl J Med 1996; 334: $1703-1708$.

6. Tanaka N, Takazawa K, Shindo N, Kobayashi K, Teramoto T, Yamashita J, et al. Decrease of fractional flow reserve shortly after percutaneous coronary intervention. Circ J 2006; 70: 1327-1331.

7. Tonino PAL, De Bruyne B, Pijls NHJ, Siebert U, Ikeno F, van't Veer $\mathrm{M}$, et al. Fractional flow reserve versus angiography for guiding percutaneous coronary intervention. N Engl J Med 2009; 360: $213-$ 224.

8. The Task Force on Myocardial Revascularization of the European Society of Cardiology (ESC) and the European Association for Cardio-Thoracic Surgery (EACTS); European Association for Percutaneous Cardiovascular Interventions (EAPCI), Wijns W, Kolh P, Danchin N, Di Mario C, Falk V, Folliguet T, et al. Guidelines on myocardial revascularization. Eur Heart J 2010; 31: 2501-2555.

9. Kern MJ, Samady H. Current concepts of integrated coronary physiology in the catheterization laboratory. J Am Coll Cardiol 2010; 55: $173-185$.

10. Kang SJ, Mintz GS, Akasaka T, Park DW, Lee JY, Kin WJ, et al. Optical coherence tomographic analysis of in-stent neoatherosclerosis after drug-eluting stent implantation. Circulation 2011; 123: $2954-$ 2963.

11. Davlouros PA, Karantalis V, Xanthopoulou I, Mavronasiou E, Tsigkas G, Toutouzas K, et al. Mechanisms of non-fatal stent-related myocardial infarction late following coronary stenting with drug-eluting stents and bare metal stents: Insights from optical coherence tomography. Circ J 2011; 75: 2789-2797.

12. Gonzalo N, Escaned J, Alfonso F, Nolte C, Rodriguez V, JimenezQuevedo P, et al. Morphometric assessment of coronary stenosis relevance with optical coherence tomography: A comparison with fractional flow reserve and intravascular ultrasound. J Am Coll Cardiol 2012; 59: 1080-1089.

13. Shiono Y, Kitabata H, Kubo T, Masuno T, Ohta S, Ozaki Y, et al. Optical coherence tomography-derived anatomical criteria for functionally significant coronary stenosis assessed by fractional flow reserve. Circ J 2012; 76: 2218-2225. 